-

\title{
O TRABALHO DE ENFERMAGEM E A ERGONOMIA
}

Maria Helena Palucci Marziale*

Maria Lúcia do Carmo Cruz Robazzi**

MARZIALE, M.H.P.; ROBAZZI, M.L.C.C. O trabalho de enfermagem e a ergonomia. Rev.latino-am.enfermagem, Ribeirão Preto, v. 8, n. 6, p. 124-127, dezembro 2000.

O presente texto articula evidências empíricas produzidas por trabalhos científicos visando a reflexão sobre a aplicação da Ergonomia como instrumento metodológico de apoio à melhoria das condições laborais dos trabalhadores de Enfermagem em hospitais.

UNITERMOS: ergonomia, trabalhador de enfermagem, condição de trabalho

Diante das inadequadas condições de trabalho oferecidas aos trabalhadores nos hospitais de muitos países, a Organização Internacional do Trabalho (OIT), desde a década de 40 , tem considerado o problema como tema de discussão e tem feito recomendações referente a higiene e segurança com a finalidade da adequação das condições de trabalho desses profissionais.

Essas condições insatisfatórias estão relacionadas à fatores biológicos, físicos, químicos, psicossociais e ergonômicos, os quais podem causar danos à saúde dos profissionais que alí atuam. Dentre esses fatores enfocaremos a seguir os ergonômicos.

Segundo CAVASSA (1997), os fatores ergonômicos são aqueles que incidem no comportamento trabalho-trabalhador. São eles o desenho dos equipamentos, do posto de trabalho, a maneira que a atividade é executada, comunicação, o meio ambiente (grau de insalubridade, iluminação, temperatura, etc.).

Segundo COUTO (1995), através da aplicação dos princípios da Ergonomia pode ser propiciada uma interação adequada e confortável do ser humano com os objetos que maneja e com o ambiente onde trabalha e ainda melhorar a produtividade, reduzir os custos laborais que se manifestam através de absenteísmo, rotatividade, conflitos e pela falta de interesse para o trabalho. No entanto, acreditamos que a mobilização dos trabalhadores e de seus sindicatos também sejam necessárias para que efetivas e profundas mudanças ocorram nas condições de trabalho.

Para a Ergonomia, as condições de trabalho são representadas por um conjunto de fatores interdependentes, que atuam direta ou indiretamente na qualidade de vida das pessoas e nos resultados do próprio trabalho.

Uma descrição detalhada dos fatores que interferem nas condições de trabalho hospitalar é encontrada no livro "Travailler à l'hospital" de autoria de ESTRYN-BEHAR \& POINSIGNON (1989). As referidas autoras mencionam o desenvolvimento rápido e contínuo da tecnologia médica, a grande variedade de procedimentos e exames realizados, o aumento constante do conhecimento teórico e prático exigido na área da saúde, a especialidade do trabalho, a hierarquização e a dificuldade de circulação de informação, o ritmo e o ambiente físico, o estresse e o contato com o paciente, a dor e a morte como elementos que potencializam a carga de trabalho, ocasionando

* Professor Associado do Departamento de Enfermagem Geral e Especializada da Escola de Enfermagem de Ribeirão Preto da Universidade de São Paulo. Endereço: Av. Bandeirantes, 3900 - Monte Alegre - 14040-902 - Ribeirão Preto - São Paulo Brasil. E-mail: marziale@glete.eerp.usp.br

** Professor Titular do Departamento de Enfermagem Geral e Especializada da Escola de Enfermagem de Ribeirão Preto da Universidade de São Paulo 
riscos à saúde física e mental dos trabalhadores do hospital.

Segundo ESTRYN-BEHAR (1996), a análise ergonômica tem sido utilizada para a adaptação dos equipamentos usados no cuidado à saúde e os estudos ergonômicos constituem-se em um caminho para a obtenção de informações específicas e relevantes sobre a melhoria da qualidade do cuidado e da qualidade de vida do trabalhador no trabalho.

A abordagem ergonômica para análise da situação de trabalho de enfermagem tem sido utilizada por estudiosos no mundo todo. No Brasil, MAURO et al. (1976) foram as pioneiras em utilizar os princípios ergonômicos para analisar o trabalho de enfermagem e na última década houve uma maior utilização da referida abordagem e um número crescente de estudos tem sido realizados.

MARZIALE (1990), estudou através da abordagem ergonômica a fadiga mental entre enfermeiras que atuavam em hospital em esquema de turnos alternantes, constatando que o referido esquema de horários era responsável pela inadaptação das enfermeiras as condições de trabalho.

BENEDITO (1994), estudou as exigências cognitivas das atividades executadas pelo pessoal de Enfermagem em um hospital escola de Santa Catarina.

FARIA (1996), investigou as fontes geradoras de sofrimento psíquico para técnicos e auxiliares de Enfermagem de um hospital público com vistas a conhecer o processo e forma de organização do trabalho através da utilização da metodologia ergonômica.

BENEDITO \& CONTIJO (1996) apresentam diversas conceitualizações para analisar os processos mentais nos desenvolvimentos de tarefas e sua adequacidade para a análise dos processos cognitivos na arte do cuidar da enfermagem.

Estudos ergonômicos tem sido realizados para analisar as posturas físicas adquiridas na execução das atividades de trabalho de Enfermagem buscando a adequação dessas atividades respeitando os princípios da Biomecânica.

ALEXANDRE e seus colaboradores tem direcionado a atenção para estudos abordando aspectos ergonômicos e posturais no transporte de paciente e em relação à ocorrência de cervicodorsolombalgias entre a equipe de Enfermagem (ALEXENDRE et al.1991; ALEXANDRE \& ANGERAMI,1993; ALEXANDRE, 1998). Através dos referidos estudos foi constatado que grande parte das agressões à coluna vertebral estão relacionadas a inadequação de mobiliários e equipamentos utilizados nas atividades cotidianas de Enfermagem e com a adoção de má postura corporal adotadas pelos trabalhadores.

ZEIROUNE (1996) estudou o desconforto lombar e as variáveis cinemáticas da postura do profissional de Enfermagem. ROCHA(1997) também voltou sua atenção ao estudo dos problemas posturais. Em sua dissertação de mestrado analisou os fatores ergonômicos e traumáticos envolvidos na ocorrência de dor nas costas em trabalhadores de Enfermagem, constatando que $89 \%$ dos trabalhadores apresentavam algum tipo de algia vertical, sendo a região lombar a mais acometida.

Diante da constatação dos problemas causados pela inadequada postura em nossa prática profissional voltamos também nossa atenção para os estudos das posturas adotadas durante a execução de determinados procedimentos técnicos executados pelo pessoal de Enfermagem MARZIALE et al. (1991); BERNARDINA et al. (1995) e MARZIALE (1999).

Outros autores abordaram aspectos gerais e metodológicos da Ergonomia. BULHÕES (1998) dedica um capítulo de seu livro sobre riscos do trabalho de Enfermagem sobre como a Ergonomia pode ajudar no trabalho. ERDMANN \& BENEDITO (1995) publicaram um artigo visando contribuir para a reflexão sobre o uso da Ergonomia como instrumento metodológico de análise no processo de trabalho de Enfermagem e SILVEIRA (1997) se utilizou das contribuições advindas da Ergonomia para formular uma proposta de metodologia de ação em Enfermagem comprometida com a relação saúde-vida laboral.

Com intuito de divulgar os princípios ergonômicos e sua aplicabilidade junto a análise do trabalho em instituições hospitalares, visando a melhorias das condições de trabalho, elaboramos o artigo intitulado "Ergonomia no hospital" (MARZIALE \& CARVALHO, 1996). Através do qual, apresentamos a evolução da Ergonomia através da história descrevendo sua importância para eliminar ou minimizar fatores sofríveis do trabalho desenvolvido por profissionais que atuam no ambiente hospitalar, permitindo a adequação das condições de trabalho às características psicofisiológicas dos trabalhadores.

MATOS (1994), estudou o trabalho do enfermeiro do centro cirúrgico através da ótica da Ergonomia com enfoque voltado a comunicação no trabalho e AMARANTE (1999), analisou as condições ergonômicas do trabalho de Enfermagem em várias unidades de centro cirúrgico dos hospitais da cidade de São Paulo.

Desta forma consideramos a aplicação dos princípios ergonômicos na Enfermagem condizentes com a fase de desenvolvimento em que esta profissão se encontra, onde o corpo de conhecimento científico, embora ainda em formação, está sendo construído, vislumbrando não apenas a técnica, mas o embasamento teórico engajado nos modelos assistenciais contextualizados no atual momento sócio-político e econômico. 


\section{ERGONOMICS AND NURSING WORK}

This text articulates empirical evidence resulting from scientific work with the intention of providing a reflection about the application of ergonomics as a methodological instrument to support improvement of the labor conditions of nursing personnel in hospitals.

KEY WORDS: ergonomics, nursing personnel, work conditions

\section{EL TRABAJO DE ENFERMERÍA Y LA ERGONOMÍA}

El presente texto articula evidencias empíricas producidas por trabajos científicos buscando la reflexión sobre la aplicación de la ergonomía como instrumento metodológico de a poyo al mejoramiento de las condiciones laborales de los trabajadores de enfermería en hospitales.

TÉRMINOS CLAVES: ergonomía, trabajador de enfermería, condición de trabajo.

\section{REFERÊNCIAS BIBLIOGRÁFICAS}

01. ALEXANDRE, N.M.C.; MORAES, M.AA.; MAHAYRI, N.; CUNHA, S.H.F. Aspectos ergonômicos e posturais no centro de materiais. Rev. Esc. Enfermagem USP, v. 26, n. 1, p. 8794, mar. 1991.

02. ALEXANDRE, N.M.C.; ANGERAMI, E.L.S. Avaliação de determinados aspectos ergonômicos no transporte de pacientes. Rev. Bras. Saúde Ocup., v. 21, n. 77, p. 81-90, jan. 1993.

03. ALEXANDRE, N.M.C. Ergonomia e as atividades ocupacionais da equipe de enfermagem. Rev. Esc. Enfermagem USP, v. 32, n. 1, p. 84-90, abr. 1998.

04. AMARANTE, S.T. Análise das condições ergonômicas do trabalho das enfermeiras de centro cirúrgico. São Paulo, 1999, 214p. Dissertação (Mestrado) - Escola de Enfermagem, Universidade de São Paulo.

05. BENEDITO, G.A.V. Análise de exigências cognitivas das atividades do trabalhador de enfermagem. Florianópolis, 1994, 166p. Dissertação (Mestrado) - Centro de Ciências da Saúde, Universidade Federal de Santa Catarina.

06. BENEDITO, G.A.V.; GONTIJO, L.A. A ergonomia cognitiva: um referencial de análise na arte do cuidar em enfermagem. Texto \& Contexto Enfermagem, v. 5, n. 1, p. 111-29, jan. 1996.

07. BERNARDINA, L.D.; MARZIALE, M.H.P.; CARVALHO, E.C.C. Postura corporal adotada pelos membros da equipe de enfermagem durante os procedimentos de colheita de sangue, administração de medicação endovenosa e soroterapia, Rev. Esc. Enfermagem USP, v. 29, n. 3, p. 317-30, dez. 1995.
07. BULHÕES, I. Riscos do trabalho de enfermagem. Rio de Janeiro, Folha Carioca, 1998. 221p.

08. CAVASSA, C.R. Ergomomia y productividad. Balderas, Limsa Noriega, 1997. 415p.

09. COUTO, H.A. Ergonomia aplicada ao trabalho: manual técnico da máquina humana. Belo Horizonte, Ergo, 1995, v. 1, 353p.

10. ERDMANN, A.L.; BENEDITO, G.A.V. A ergonomia como instrumento no processo de trabalho de enfermagem. Texto \& Contexto Enfermagem, v. 4, n. 1, p. 41-6, jan./jun. 1995.

11. ESTRYN-BEHAR, M.; POINSIGNON, H. Travailler à l'hôpital. Paris, Berger Levrault, 1989.181p.

12. ESTRYN-BEHAR, M. Ergonomia hospitalar: teoria e prática. In: ENCONTRO NACIONAL DE ENFERMAGEM DO TRABALHO, 7, Rio de Janeiro, 1996. Anais. Rio de Janeiro, 1996. p. 96-105.

13. FARIA, M.F.S. O trabalho hospitalar e saúde: estudo de caso de técnicos e auxiliares de Enfermagem em instituição de pediatria. Rio de Janeiro.1996. 103p. Dissertação (Mestrado) Escola Nacional de Saúde Pública.

14. MARZIALE, M.H.P. Estudo da fadiga mental de enfermeiras atuantes em instituição hospitalar com esquema de trabalho em turnos alternantes. 1990, p.132. Dissertação (Mestrado) - Faculdade de Filosofia Ciências e Letras de Ribeirão Preto, Universidade de São Paulo.

15. MARZIALE, M.H.P.; MELO, M.R.A.C.; SILVA, E,M. A postura corporal adotada pela enfermeira durante a execução de seu trabalho, Rev. Bras. Saúde Ocup., v. 19, n. 73, abr./maio/jun. 1991. 
MARZIALE, M.H.P.; ROBAZZI, M.L.C.C. O trabalho de... Rev. latino-am. enfermagem - Ribeirão Preto - v. 8 - n. 6 - p. $124-127$ - dezembro 2000

127

16. MARZIALE, M.H.P.; CARVALHO, E.C. A ergonomia no hospital. Rev. CIPA, n. 196, p. 98-108, 1996.

17. MARZIALE, M.H.P. Abordagem ergonômica do trabalho de enfermagem. 1999, p. 149. Texto (Livre-Docência) - Escola de Enfermagem de Ribeirão Preto, Universidade de São Paulo.

18. MATOS, D.G. O trabalho do enfermeiro do centro cirúrgico: um estudo sob a ótica da ergonomia. Brasília, 1994. 160p. Dissertação (Mestrado) Instituto de Psicologia, Universidade de Brasília.

19. MAURO, M.Y.C. et al. Fadiga e aspectos ergonômicos no trabalho de enfermagem. Rev. Bras. Enfermagem, v. 29, n. 1, p. 7-18, 1976.
20. ROCHA, A.M. Fatores ergonômicos e traumáticos envolvidos na ocorrência de dor nas costas em trabalhadores de enfermagem. Belo Horizonte. 1997, 151p. Dissertação (Mestrado) - Escola de Enfermagem, Universidade Federal de Minas Gerais.

21. SILVEIRA, D.T. Consulta-ação: educação e reflexão nas intervenções de enfermagem no processo trabalho-saúde-adoecimento. Porto Alegre, 1997. 154p. Dissertação (Mestrado) Programa de Mestrado em Assistência em Enfermagem, Universidade de Santa Catarina.

22. ZEIHOUNE, R.C.G. Desconforto lombar e as variáveis cinemáticas da postura do profissional de enfermagem. 1996, Tese (Doutorado) - Escola de Enfermagem Anna Nery, Universidade Federal do Rio de Janeiro. 